\title{
Opioid peptides decrease calcium-dependent action potential duration of mouse dorsal root ganglion neurons in cell culture
}

\author{
MARY ANN WERZ* and ROBERT L. MACDONALD $\$$ \\ Neurosciences Program and (R.L.M.) Department of Neurology, University of Michigan Medical \\ Center, Neuroscience Laboratory Building, 1103 E. Huron, Ann Arbor, MI 48109 (U.S.A.)
}

(Accepted January 14th, 1982)

Key words: opioid peptide - calcium action potential — sensory ganglion neuron - cell culture

We investigated opioid peptide actions on somatic calcium-dependent action potentials of dorsal root ganglion (DRG) neurons grown in primary dissociated cell culture. We report that leucine-enkephalin decreased the duration and amplitude of DRG somatic calcium-dependent action potentials. The opioid peptide action was dose-dependent over $20 \mathrm{nM}$ to $5 \mu \mathrm{M}$ and was antagonized by naloxone, consistent with mediation by opiate receptors. Thus, DRG neuron membranes have opiate receptors which act to decrease calcium influx. It is likely, therefore, that opiate receptors on the somata of DRG neurons in culture are functionally similar to opiate receptors on primary afferent terminals.

Opiates can act directly at the level of the spinal cord to produce analgesia ${ }^{37}$. The mechanism of opiate mediated analgesia at spinal levels is thought to involve depression of neurotransmitter release from primary afferents conveying nociceptive information $4,7,8,11,12,19,23,26,29,32$. Release of neurotransmitter is associated with activation of voltage-dependent calcium conductance in synaptic terminal membranes ${ }^{21,24,25}$. It has been suggested that opiates depress neurotransmitter release by reducing presynaptic calcium entry ${ }^{5,13-15,29}$. However, presynaptic opiate actions to decrease calcium influx ${ }^{5,13-15}$ cannot be investigated directly since intracellular recording techniques cannot be applied to primary afferent synaptic terminals. The somatic membrane of dorsal root ganglion (DRG) neurons has a voltage-dependent calcium conductance $e^{6,10,18,27,28,30}$ which is sensitive to a variety of neurotransmitters $\mathbf{9}^{9,10,29}$. Thus, the DRG neuron soma membrane, with the advantage of permitting study by intracellular recording, has been proposed as a model for synaptic terminal membrane (refs. 9, 10, 29). If the model is valid, transmitter effects on DRG neuron somatic calcium-dependent action potentials reflect effects on calcium entry at synaptic terminals and, hence, on transmitter release. The use of somatic membrane as a model for terminal membrane has been supported by several studies $9,10,17,22,29$.

\footnotetext{
* This work was submitted in partial fulfillment of the requirements for the degree of Doctor of Philosophy in Neurosciences at the University of Michigan by M.A.W.

$\S$ To whom all correspondence should be addressed.
} 
Mudge et al. ${ }^{29}$ recently demonstrated that the opioid peptide, D-Ala ${ }^{2}-$ Met-enkephalinamide decreased the duration and amplitude of somatic calcium-dependent action potentials in chick DRG neurons grown in primary dissociated cell culture, an action correlated with a reduction of substance $P$ release. This finding has not been confirmed since the calcium component of action potentials was unaltered by enkephalins in other studies $16,33,36$. In this study, we used intracellular recording techniques to investigate the actions of leucine-enkephalin (L-ENK) on somatic action potential of murine DRG neurons grown in primary dissociated cell culture. We report that L-ENK at $20 \mathrm{nM}$ to $5 \mu \mathrm{M}$ decreased the duration and amplitude of the calcium component of DRG action potentials. The opioid peptide effect was dosedependent and antagonized by naloxone, consistent with mediation by opiate receptors.

Cell cultures used in these experiments were prepared from spinal cords with attached dorsal root ganglia dissected from 13-14-day-old fetal mice as previously described $^{31}$. Experimental medium was a balanced salt solution containing (in $\mathrm{mM}$ ): $\mathrm{NaCl}, 137 ; \mathrm{KCl}, 5.3 ; \mathrm{MgCl}_{2}, 0.8 ; \mathrm{CaCl}_{2}, 5.0$; Tris-hydrochloride, 15; glucose, 5.6; tetraethylammonium-chloride (TEA), 5.0. TEA, which decreases voltage-dependent potassium conductance ${ }^{1}$, was used to enhance the calcium component of DRG neuron action potentials ${ }^{18}$. In TEA-free medium DRG neuron somatic action potential duration was about $2.0 \mathrm{~ms}$ with the initial $0.6 \mathrm{~ms}$ dependent upon sodium and the remainder upon calcium ${ }^{18}$. Medium containing $5 \mathrm{mM}$ TEA increased the duration of the calcium component to 3-25 ms. Thus, in TEA-containing medium, the sodium component of action potentials is brief in comparison to the calcium component.

Aliquots of L-ENK (Calbiochem-Behring Corporation or Sigma Chemical Company), dissolved in distilled water at $1 \mathrm{mM}$ and frozen in plastic tubes, were thawed and serially diluted in experimental medium to appropriate concentrations. DRG neurons were impaled with high resistance (20-40 M $\Omega$ ) glass micropipettes filled

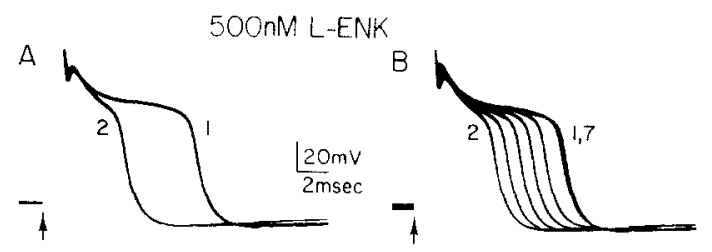

Fig. 1. L-ENK decreases the duration and amplitude of the calcium component of DRG neuron somatic action potentials. Depolarizing current pulses (applied at arrow) evoked action potentials from resting membrane potential at $15 \mathrm{~s}$ intervals. Action potentials evoked in medium containing 5 $\mathrm{mM}$ TEA had durations of $520 \mathrm{~ms}$ and were dependent upon both sodium and calcium. Approximately the first millisecond is dependent upon sodium with the remaining broad plateau dependent upon calcium. A: data in this and following figures are superimposed action potentials evoked prior to (1) and subsequent to (2) L-ENK application. Control action potential duration was $11 \mathrm{~ms}(1)$, measured from onset of the depolarizing stimulus to the point where potential during repolarization intersected with resting membrane potential. Pressure ejection of $500 \mathrm{nM}$ L-ENK for 1 $s$ and delivered $4 \mathrm{~s}$ prior to evoking an action potential decreased the duration and amplitude of the calcium-dependent action potential to $6 \mathrm{~ms} \mathrm{(2).} \mathrm{B:} \mathrm{action} \mathrm{potential} \mathrm{duration} \mathrm{returned} \mathrm{to} \mathrm{baseline} \mathrm{over}$ the next $1.5 \mathrm{~min}(7)$. Resting membrane potential was $-61 \mathrm{mV}$. 
with $4 \mathrm{M}$ potassium acetate and somatic calcium-dependent action potentials were evoked from resting membrane potential with $100 \mu$ s depolarizing current pulses at a frequency of $4 / \mathrm{min}$. L-ENK was applied by pressure ejection $(0.5-2.0 \mathrm{psi})$ from micropipettes with tip diameters of $2-5 \mu \mathrm{m}$. Naloxone (Endo Laboratories) was applied by diffusion from $15-25 \mu \mathrm{m}$ diameter micropipettes positioned approximately $10-15 \mu \mathrm{m}$ from the DRG. Three micropipettes were routinely used during experiments which allowed dose-dependent peptide and naloxone actions to be assessed on single neurons.

A $1 \mathrm{~s}$ application of L-ENK at $1 \mu \mathrm{M}$ delivered 3-4s prior to evoking an action potential, did not affect action potential duration or configuration in $26 \%(n=115)$ of DRG neurons. In the remaining cells, the calcium component of action potentials was decreased in amplitude and duration (Fig. 1A). The proportion of DRG neurons which responded to the opioid peptide appeared to vary as a function of culture dissection. That is, in all cultures derived from a single dissection, a similar percentage of DRG neurons responded to L-ENK. Some dissections produced cultures in which almost no neurons responded, while others produced cultures with the majority of neurons responding. The culture variable affecting DRG neuronal opiate sensitivity is unclear.

Of the neurons which responded to L-ENK ( 84 of 115 responded to $1 \mu \mathrm{M}$ ), the magnitude of the effect on DRG somatic calcium-dependent action potentials varied considerably across neurons with effects produced by $1 \mu \mathrm{M}$ L-ENK ranging from 2 to $61 \%$, with a mean reduction of $18 \%$. Action potential duration was decreased maximally immediately after application of L-ENK and then gradually returned to baseline duration over the next 1-2 min (Fig. 1B). Two to three minutes routinely separated successive applications of L-ENK. Using this paradigm the opioid peptide effect did not desensitize with repeated applications.

It is unlikely that the observed decreases in action potential duration were due to pressure artifact. Firstly, decreases in action potential duration were not obtained by pressure ejection of control medium as long as care was taken to avoid osmolarity differences between the culture bathing medium and the medium contained in micropipettes for pressure ejection. Secondly, we have also observed L-ENK-mediated decreases in action potential duration when the opioid peptide was applied by superfusion.

Multiple concentrations of L-ENK tested on single DRG neurons produced dose-dependent decreases in the duration of somatic calcium-dependent action potentials over $20 \mathrm{nM}$ to $5 \mu \mathrm{M}(\mathrm{n}=23)$ (Fig. 2). L-ENK-mediated decreases in action potential duration were tested for sensitivity to naloxone antagonism. The paradigm followed was to obtain a control response to a $1 \mathrm{~s}$ application of L-ENK. Then a naloxone-containing micropipette was positioned near the DRG neuron which allowed the antagonist to diffuse into the medium surrounding the cell after which LENK was reapplied. Finally, the naloxone-containing micropipette was removed from its position near the DRG neuron, and L-ENK was reapplied. Naloxone reversibly antagonized decreases in calcium-dependent action potentials produced by L-ENK in a dose-dependent manner when tested on single DRG neurons $(n=26)$. Reliable antagonism of $1 \mu \mathrm{M}$ L-ENK responses was produced by $1 \mu \mathrm{M}$ naloxone (Fig. 3). 


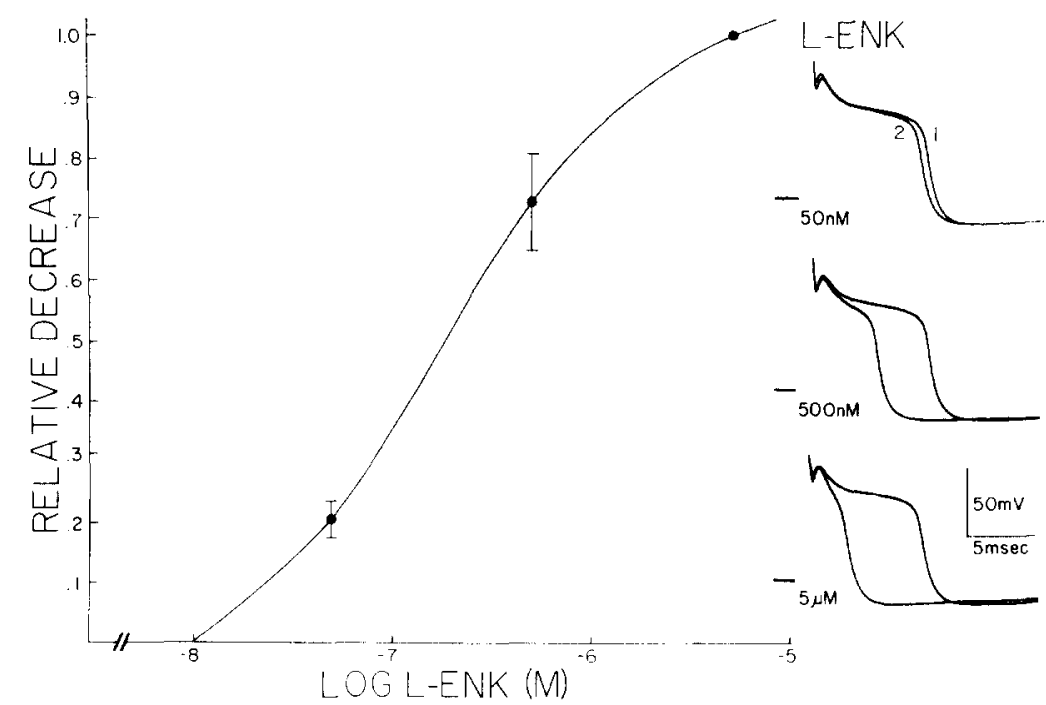

Fig. 2. L-Enk reduced the duration of DRG neuron somatic calcium-dependent action potentials dose-dependently. Semilogarithmic plot of dose-dependent actions of L-ENK. Data represent mean responses of 6 DRG neurons each tested with 3 concentrations of L-ENK and which responded to 5 $\mu \mathrm{M}$ L-ENK with reductions in action potential duration greater than $20 \%$. Mean reduction in action potential duration of the 6 neurons by $5 \mu \mathrm{M}$ L-ENK was $44 \%$ with a range of $24-57 \%$. Since the magnitude of responses to L-ENK was highly variable from cell to cell, the data are plotted as response relative to that produced by $5 \mu \mathrm{M}$ L-ENK. L-ENK-induced decreases in the duration of calcium-dependent action potentials was underestimated since measurement of action potential duration included the delay in onset of the action potential as well as the duration of the sodium component. Bars represent standard error of the mean. Data are from 5 cultures and 5 sets of L-ENKcontaining micropipettes. Dose-dependent action of L-ENK on a single DRG neuron is shown. Resting membrane potential was $-65 \mathrm{mV}$.

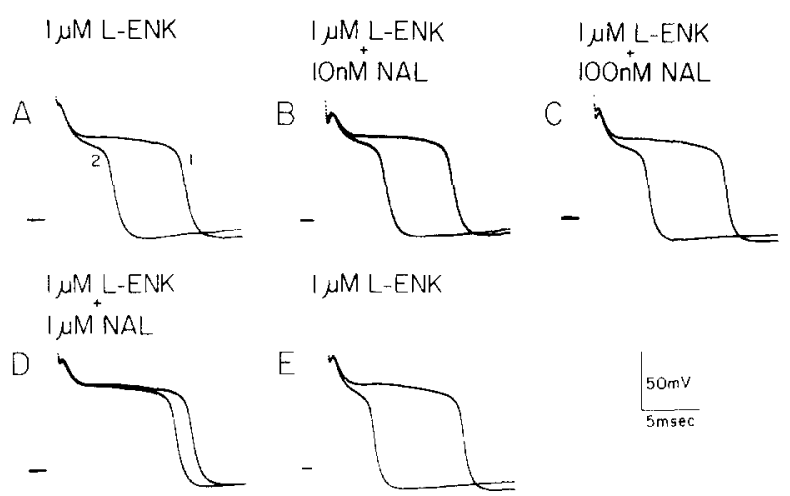

Fig. 3. Naloxone antagonized L-ENK-induced decreases in DRG neuron somatic calcium-dependent action potential duration. Action potential duration was decreased from 12 to $6 \mathrm{~ms}$ following application of $1 \mu \mathrm{M}$ L-ENK (A). After action potential duration had returned to baseline, a micropipette with tip diameter of about $20 \mu \mathrm{m}$ and containing $10 \mathrm{nM}, 100 \mathrm{nM}$ or $1 \mu \mathrm{M}$ naloxone (NAL) was positioned to within $20 \mu \mathrm{m}$ of the neuron. The naloxone was permitted to diffuse from the micropipette for $1 \mathrm{~min}$ prior to application of L-ENK. Naloxone did not antagonize L-ENK responses at $10 \mathrm{nM}(\mathrm{B})$ or $100 \mathrm{nM}(\mathrm{C})$ but did at a concentration of $1 \mu \mathrm{M}$ (D). Following removal of the $1 \mu \mathrm{M}$ naloxone containing micropipette from its position near the cell, application of L-ENK again decreased the duration of the calcium component of the action potential (E). Resting membrane potential was $-63 \mathrm{mV}$. 
We observed that L-ENK decreased the duration and amplitude of DRG neuron somatic calcium-dependent action potentials. L-ENK effects were dose-dependent and antagonized by naloxone, consistent with mediation by opiate receptors. Our findings correspond with those of Mudge et al. ${ }^{29}$ who determined that D-Ala ${ }^{2}$-Metenkephalinamide decreased the calcium component of action potentials of chick DRG neurons in cell culture; in contrast, Williams and Zieglgänsberger ${ }^{36}$ determined that opioid peptides did not affect calcium-dependent action potentials of adult DRG somata. Technical differences may account for the different results. Alternatively, the results may be a function of the preparation used. While DRG somata grown in primary dissociated culture have been demonstrated in this study to have functional opiate receptors, adult DRG neuron somata may lack such receptors in vivo. In either case, the somatic membrane of cultured DRG neurons with functional opiate receptors which act to decrease calcium influx may provide a model system for investigation relevant to mechanisms of opiate action to decrease transmitter release from primary afferents.

Opiates have been shown to decrease transmitter release $2,3,19,20,26,29,34,35$, an action correlated with decreased calcium influx into synaptic terminals ${ }^{5,13-15}$. Opiates have also been shown to decrease transmitter release from terminals of DRG neurons grown in primary dissociated cell culture ${ }^{26,29}$, an action correlated with reduction of the calcium component of DRG somatic action potentials (Mudge et al. ${ }^{29}$ and this study). Therefore, it is likely that the somata of DRG neurons grown in culture have opiate receptors which functionally are similar to synaptic terminal opiate receptors. Intracellular recording techniques cannot be applied to synaptic terminals of DRG neurons, making it impossible to directly study presynaptic opiate mechanisms. However, intracellular recording techniques can be applied to DRG neuron somata to investigate the pharmacological characteristics of opiate receptors on single DRG neurons as well as the coupling of opiate receptors with membrane ionic channels.

The authors thank Kathy Lundquist for her excellent secretarial assistance and Patricia Szczepanski-Marquardt for her skillful maintenance of the neuronal cell cultures. M.A.W. was supported by NIMH-NRSA 12479 Fellowship and by a University of Michigan Rackham Predoctoral Fellowship. R.L.M. was supported in part by NIH Research Career Development Award NS 00480. The research was supported in part by NIH Grant NS 15225 (R.L.M.).

1 Armstrong, C. M. and Binstock, L., Anomalous rectification in the squid giant axon injected with tetraethylammonium chloride, J. gen. Physiol., 48 (1965) 859-872.

2 Brennan, M. J. W., Cantrill, R. C. and Wylie, B. A., Modulation of synaptosomal GABA release by enkephalin, Life Sci., 27 (1980) 1097-1101.

3 Bornstein, J. C. and Fields, H. L., Morphine presynaptically inhibits a ganglionic cholinergic synapse, Neurosci. Lett., 15 (1979) 77-82.

4 Calvillo, O., Henry, J. L. and Neuman, R. S., Effects of morphine and naloxone on dorsal horn neurones in the cat, Canad. J. Physiol. Pharmacol., 52 (1974) 1207-1211.

5 Cardenas, H. L. and Ross, D. H., Calcium depletion of synaptosomes after morphine treatment, Brit. J. Pharmacol., 57 (1976) 521-526. 
6 Dichter, M. A. and Fischbach, G. D., The action potential of chick dorsal root ganglion neurones maintained in cell culture, J. Physiol. (Lond.), 267 (1977) 281-298.

7 Duggan, A. W., Hall, J. G. and Headley, P. M., Morphine, enkephalin and the substantia gelatinosa, Nature (Lond.), 264 (1976) 456-458.

8 Duggan, A. W., Hall, J. G. and Headley, P. M., Suppression of transmission of nociceptive impulses by morphine: selective effects of morphine administered in the region of the substantia gelatinosa, Brit. J. Pharmacol., 61 (1977) 65-76.

9 Dunlap, K. and Fischbach, G. D., Neurotransmitters decrease the calcium component of sensory neurone action potentials, Nature (Lond.), 276 (1978) 837-839.

10 Dunlap, K. and Fischbach, G. D., Neurotransmitters decrease the calcium conductance activated by depolarization of embryonic chick sensory neurones, J. Physiol. (Lond.), 317 (1981) 519-535.

11 Fields, H. L., Emson, P. C., Leigh, B. K., Gilbert, R. F. T. and Iversen, L. L., Multiple opiate receptor sites on primary afferent fibres, Nature (Lond.), 284 (1980) 351-353.

12 Gamse, R., Holzer, P. and Lembeck, F., Indirect evidence for presynaptic location of opiate receptors on chemosensitive primary sensory neurons, Naunyn-Schmiedeberg's Arch. Pharmacol., 308 (1979) 281-285.

13 Guerrero-Munoz, F., Cerreta, K. V., Guerrero, M. L. and Way, E. L., Effects of morphine on the synaptosomal calcium uptake, J. Pharmacol. exp. Ther., 209 (1979) 132-136.

14 Guerrero-Munoz, F., Guerrero, M. L., Way, E. L. and Li, C. H., Effect of $\beta$-endorphin on calcium uptake in the brain, Science, 206 (1979) 89-91.

15 Guerrero-Munoz, F., Guerrero, M. L. and Way, E. L., Effect of morphine on calcium uptake by lysed synaptosomes, J. Pharmacol. exp. Ther., 211 (1979) 370-374.

16 Haas, H. L. and Gähwiler, B. H., Do enkephalins directly affect calcium-spikes in hippocampal pyramidal cells? Neurosci. Lett., 19 (1980) 89-92.

17 Heyer, E. J. and Macdonald, R. L., Barbiturate reduction of calcium-dependent action potentials: correlation with anesthetic action, Brain Research, in press.

18 Heyer, E. J. and Macdonald, R. L., Calcium- and sodium-dependent action potentials in mouse spinal cord and dorsal root ganglion neurons in cell culture, $J$. Neurophysiol., 47 (1982) 641-655.

19 Jessell, T. M. and Iversen, L. L., Opiate analgesics inhibit substance P release from rat trigeminal nucleus, Nature (Lond.), 268 (1977) 549-551.

20 Jhamandas, K. and Sutuk, M., Action of enkephalin analogues and morphine on brain acetylcholine release: differential reversal by naloxone and an opiate pentapeptide, Brit. J. Pharmacol., 71 (1980) 201-210.

21 Katz, B. and Miledi, R., A study of synaptic transmission in the absence of nerve impulse, $J$. Physiol. (Lond.), 192 (1967) 407-436.

22 Klein, M. and Kandel, E. R., Presynaptic modulation of voltage-dependent $\mathrm{Ca}^{2+}$ current: mechanism for behavioral sensitization in Aplysia californica, Proc. nat. Acad. Sci. U.S.A., 75 (1978) 3512-3516.

23 Lamotte, C., Pert, C. B. and Snyder, S. H., Opiate receptor binding in primate spinal cord: distribution and changes after dorsal root section, Brain Research, 112 (1976) 407-412.

24 Llinas, R., Steinberg, I. Z. and Walton, K., Presynaptic calcium currents and their relation to synaptic transmission: voltage clamp study in squid giant synapse and theoretical model for the calcium gate, Proc. nat. Acad. Sci. U.S.A., 73 (1976) 2918-2922.

25 Llinas, R., Steinberg, I. Z. and Walton, K., Relationship between presynaptic calcium current and postsynaptic potential in squid giant synapse, Biophys. J., 33 (1981) 323-352.

26 Macdonald, R. L. and Nelson, P. G., Specific opiate-induced depression of transmitter release from dorsal root ganglion cells in culture, Science, 199 (1978) 1449-1451.

27 Matsuda, Y., Yoshida, S. and Yonezawa, T., A Ca-dependent regenerative response in rodent dorsal root ganglion cells cultured in vitro, Brain Research, 115 (1976) 334-338.

28 Matsuda, Y., Yoshida, S. and Yonezawa, T., Tetrodotoxin sensitivity and Ca component of action potentials of mouse dorsal root ganglion cells cultured in vitro, Brain Research, 154 (1978) 69-82.

29 Mudge, A. W., Leeman, S. E. and Fischbach, G. D., Enkephalin inhibits release of substance P from sensory neurons in culture and decreases action potential duration, Proc. nat. Acad. Sci. U.S.A., 76 (1979) 526-530.

30 Ransom, B. R. and Holz, R. W., Ionic determinants of excitability in cultured dorsal root ganglion and spinal cord cells, Brain Research, 136 (1977) 445-453.

31 Ransom, B. R., Neale, E., Henkart, M., Bullock, P. N. and Nelson, P. G., Mouse spinal cord in 
cell culture. I. Morphology and intrinsic neuronal electrophysiologic properties, J. Neurophysiol., 40 (1977) 1132-1150.

32 Sastry, B. R., Presynaptic effects of morphine and methionine-enkephalin in feline spinal cord, Neuropharmacol., 18 (1979) 367-375.

33 Shefner, S. A., North, R. A., Zukin, R. S., Opiate effects on rabbit vagus nerve: electrophysiology and radioligand binding, Brain Research, 221 (1981) 109-116.

34 Subramanian, N., Mitznegg, P., Sprügel, W., Domschke, W., Domschke, S., Wünsch, E. and Demling, L., Influence of enkephalin on $\mathrm{K}^{+}$-evoked efflux of putative neurotransmitters in rat brain, Naunyn-Schmiedeberg's Arch. Pharmacol., 299 (1977) 163-165.

35 Taube, H. D., Borowski, E., Endo, T. and Starke, K., Enkephalin: a potential modulator of noradrenaline release in rat brain, Europ. J. Pharmacol., 38 (1976) 377-380.

36 Williams, J. and Zieglgänsberger, W., Mature spinal ganglion cells are not sensitive to opiate receptor mediated actions, Neurosci. Lett., 21 (1981) 211-216.

37 Yaksh, T. L. and Rudy, T. A., Analgesia mediated by a direct spinal action of narcotics, Science, 192 (1976) 1357-1358. 